\title{
Conversion of a Severe Environmental Pollutant Electric Arc Furnace Dust (EAFD) to a Valuable Corrosion Inhibitor for Steel in Chloride Contaminated Reinforced Concrete Structures
}

\section{Raja Rizwan Hussain* \\ Assistant Professor in CoE-CRT, Civil Engineering Department, College of Engineering at King Saud University, Riyadh, Saudi Arabia}

EAFD is a hazardous solid waste and environmental pollutant which is generated in the collection of particulate material during steelmaking process via electric arc furnace. It is a fine powder passed through cooling pipes and then filled and kept in specially designed bag filters. The world generation of EAFD is estimated to be around 3.7 million tons per year. Such significant quantity is due to the fact that for every ton of recycled steel an amount of 15-20 kg of EAFD is produced $[1,2]$. It had been a problem for many years as it acquires a fair deal of money to be taken care of and to save the environment from its polluting effects. The cost of EAFD disposal is not negligible. For example, 200 million dollars per year are necessary to dispose EAFD in the United States [3-5].

EAFD characterization showed that it contained mainly zinc oxide (zincite- $\mathrm{ZnO}$ ) and zinc ferrite (franklinite- $\mathrm{ZnFe} 2 \mathrm{O} 4$ ). The largest metallic portion of the EAFD is zinc, which varies between 7 and $40 \%$, depending on the ratio of galvanized scrap utilized $[1,6,7]$. The presence of this $\mathrm{ZnO}$ in EAFD makes it a significant solution to the problem of steel corrosion in concrete [8-10]. It is mentioned in the literature [9] that zinc oxide present in EAFD may act as a corrosion inhibitor. Also, the presence of calcium oxide in EAFD increases the amount of calcium hydroxide in concrete which raises its $\mathrm{pH}$ value and is also a corrosion delayer since the initiation of corrosion requires that the solution surrounding the reinforcement steel have a relatively low $\mathrm{pH}$ value. But, the findings are introductory and further research is needed in these areas to investigate and verify such phenomena.

Over the years EAFD has been disposed off through stabilization and/or consolidation processes [1,3,6]. Fahad Al-Mutlaq and Y. Du [11] have studied and have recommended EAFD as a good addition to the concrete as it enhances its durability. B Pavao et al [12] have recommended the potentiality of EAFD as an eco-friendly binder enhancing the durability of concrete. Some researchers $[4,13]$ have proposed a leaching and stabilization model for EAFD. Alexandre $S$ de Vargas et al. [14] have stated that EAFD enhances the concrete resistivity at advanced ages.

Several methods have been proposed to control corrosion of reinforcing steel in concrete structures. One of these is to stop/reduce diffusion of aggressive agents such as $\mathrm{Cl}-$, SO42-, $\mathrm{CO} 2$, etc. which mainly depend on the permeability of the concrete. Efforts should be made to reduce this by incorporating various 'supplementary cementitious materials' (SCMs) or 'mineral admixtures', such as EAFD. In Saudi Arabia, EAFD is produced in fairly large quantities. Research works done in Saudi Arabia [3] have suggested that the incorporation of EAFD in concrete, as a cement replacement material or as an admixture, can improve its durability and other mechanical properties of concrete. However, the time dependent detailed investigation of the effect of EAFD on corrosion potential and current is still very limited.

The aim of future research should be to show that the incorporation of EAFD in reinforced concrete will be a successful means to improve the corrosion durability performance of reinforced concrete. The use of EAFD will also have significant environmental and economical benefits as a partial substitution of Portland cement clinker, which has high $\mathrm{CO}_{2}$ emissions generated during manufacture. There is believed to be considerable need for further research into the possibility of applying alternative by-product materials as SCMs or mineral admixtures in concrete for long term durability tests such as corrosion inhibition. The element of future research which will make it different and prominent from the rest is the long term time dependent study of reinforced concrete durability with regards to corrosion protection by the addition of EAFD.

Therefore, the main objectives of future research should be to investigate the effect of electric arc furnace dust on corrosion of steel in chloride contaminated concrete by clarifying the mechanisms involved therein. This electrochemical-thermodynamic phenomenon is influenced by several factors and some of them are being overlooked in the past research works and have difference of opinion, especially when it comes to the time dependent long term corrosion protection of reinforced concrete. Also it was found that the experimental data for the long term effect of EAFD on corrosion of steel in concrete is limited $[3,15]$. For this purpose corrosion potential and corrosion current profiles as a function of time need to be determined experimentally for several years.

Electric arc furnace dust from steel production is generated in considerable amounts worldwide. It contains some heavy metals and thus is classified as environmentally hazardous material. With the large increase in steel production using EAF technology during the last few years, the problem of managing EAFD is now a serious environmental challenge both locally and internationally. The ultimate goal of future research should be to develop and facilitate utilization of EAFD in reinforced concrete construction as a safe, economical and attractive way for disposing of this hazardous and environmental pollutant.

Corrosion inhibitive effect of EAFD on steel reinforced chloride contaminated concrete structures varies in a complex non linear manner with the passage of time and age of concrete. It was found that the gradient of corrosion profile becomes significantly steep with the increase in EAFD concentration. Influential parameters for the effect of EAFD on corrosion prevention in reinforced concrete structures involving the severe environmental loading of chloride ions should be experimentally determined and discussed through parametric study. The experiment results of past research confirm that the EAFD has a corrosion inhibiting effect on concrete. This effect is temporary

*Corresponding author: Raja Rizwan Hussain, Assistant Professor in CoE-CRT, Civil Engineering Department, College of Engineering at King Saud University, Riyadh, Saudi Arabia, Tel: +966-590011078; E-mail: raja386@hotmail.com

Received July 29, 2013; Accepted August 01, 2013; Published August 06, 2012

Citation: Hussain RR (2013) Conversion of a Severe Environmental Pollutant Electric Arc Furnace Dust (EAFD) to a Valuable Corrosion Inhibitor for Steel in Chloride Contaminated Reinforced Concrete Structures. J Civil Environ Eng 3: e111. doi:10.4172/2165-784X.1000e111

Copyright: (c) 2013 Hussain RR. This is an open-access article distributed under the terms of the Creative Commons Attribution License, which permits unrestricted use, distribution, and reproduction in any medium, provided the original author and source are credited. 
and EAFD concrete in aggressive environment will have a stronger resistance to corrosion but will eventually become like normal concrete. This means added years of service and delayed failure due to corrosion which is desirable. EAFD is a hazardous environmental pollutant and should not be allowed in the environment untreated. As an outcome of past research, the corrosion inhibition effect of EAFD provides an economical and beneficial way to get rid of this hazardous material by using it as a valuable additive to the reinforced concrete. Scanning electron microscopic images and energy dispersive $\mathrm{x}$-ray analysis has shown in the past that the quality of concrete matrix improves by the addition of electric arc furnace dust which attributes corrosion protection. EAFD reduces the rate of corrosion by increasing the $\mathrm{Cl}^{-}$ binding capacity and alkalinity of concrete due to increased hydroxyl ion concentration in pore solution as well as by reducing the porosity itself. The effect of EAFD on the corrosion rate is non-linear depending on the $\%$ age of EAFD and $\mathrm{Cl}^{-} / \mathrm{OH}^{-}$ratio. Both chloride binding and hydroxyl ion concentration increase with hydration time of EAFD concrete. This results in reducing the $\mathrm{Cl}^{-} / \mathrm{OH}^{-}$ratio, which implies that the risk of chloride-induced corrosion of reinforcing steel is reduced with EAFD addition in concrete. This needs further deep investigation and remains as a scope for future research.

\section{References}

1. Oustadakis P, Tsakiridis PE, Katsiapi A, Agatzini-Leonardou A (2010) Hydrometallurgical process for zinc recovery from electric arc furnace dust (EAFD). Part I: Characterization and leaching by diluted sulphuric acid. J Hazardous Mat 179: 1-7.

2. Laforest G, Duchesne J (2006) Characterization and leachability of electric arc furnace dust made from remelting of stainless steel. J Hazardous Mat 135 $156-164$

3. Al-Zaid RZ, Al-Sugair FH, Al-Negeimish Al (1997) Investigation of potentia uses of electric arc furnace dust (EAFD) in concrete. Cement Concrete Res 27: $267-278$

4. Sebag MG, Korzenowski C, Bernardes AM, Vilela AC (2009) Evaluation of environmental compatibility of EAFD using different leaching standards. J Hazardous Mat 166: 670-675

5. Niubó M, Fernández AL, Chimenos JM, Haurie $L$ (2009) A possible recycling method for high grade steels EAFD in polymer composites. J Hazardous Mat 171: $1139-1144$

6. Pereira FC, Luna Galiano Y, Rodríguez-Piñero MA, Parapar JV (2007) Long and short-term performance of a stabilized/solidified electric arc furnace dust. J Hazardous Materials 148: 701-707.

7. Machado JGMS, Brehm FA, Moraes CAM, Santos CA, Vilela ACF, Cunha JBM (2006) Chemical, physical, structural and morphological characterization of the electric arc furnace dust. J Hazardous Materials 136: 953-960.

8. Brown HE (1957) Zinc Oxide Rediscovered. New York: The New Jersey Zinc Company.

9. Amuda $\mathrm{MOH}$, Fashanu TA, Lawal GI, Soremekun OO (2006) Collaborative Influence of Zinc Oxide and Triethylene Amine on the Corrosion Behavior of Mild Steel in Hydrogen Cyanide Environment. Leonardo Electron J Practices and Tech 25-32.

10. Tsakiridis PE, Oustadakis P, Katsiapi A, Agatzini-Leonardou S (2010) Hydrometallurgical process for zinc recovery from electric arc furnace dust (EAFD). Part II: Downstream processing and zinc recovery by electrowinning. J Hazardous Materials 179: 8-14.

11. Al-Mutlaq F, Du Y, Page CL (2009) Effect of Electric Arc Furnace Bag House Dust on Concrete Durability. Project: Saudi Basic Industries Corporation (SABIC).

12. Pavao B, De Vargas AS, Masuero AB, Dal Molin DC, Vilela AC (2009) Influence Of Electric Arc Furnace Dust (EAFD) In Alkali-Activated Fly Ash Binder. Proceedings of the $11^{\text {th }}$ International Conference on Non-conventional Materials and Technologies (NOCMAT) UK.

13. Salihoglu G, Pinarli V (2008) Steel foundry electric arc furnace dust management: Stabilization by using lime and Portland cement. J Hazardous Material 153: 1110-1116.

14. De Vargas AS, Ângela B. Masuero and Antônio C.F. Vilela (2006) Investigations on the use of electric-arc furnace dust (EAFD) in Pozzolan-modified Portland cement I (MP) pastes. Cement Concrete Res 36: 1833-1841.

15. Andrade C, Alonso C, Sarr J (2002) Corrosion Rate Evolution in Concrete Structures Exposed to the Atmosphere. Cement Concrete Compos 24: 55-64. 